\title{
Deconvolution of Gas Diffusion Polarization in Ni/Gadolinium-Doped Ceria Fuel Electrodes
}

\author{
C. Grosselindemann ${ }^{\mathrm{a}}$, N. Russner ${ }^{\mathrm{a}}, \mathrm{S}$. Dierickx ${ }^{\mathrm{a}}$, and A. Weber ${ }^{\mathrm{a}}$ \\ ${ }^{a}$ Institute for Applied Materials - Electrochemical Technologies (IAM-ET), \\ Karlsruhe Institute of Technology (KIT), Karlsruhe, D-76131, Germany
}

\begin{abstract}
The deconvolution of physicochemical processes in impedance spectra of SOCs with nickel/ceria fuel electrodes is challenging as gas diffusion strongly overlaps with the electrochemical processes at fuel and air electrode. To overcome this issue, symmetrical cells were applied and the gas diffusion process at the fuel electrode was quantified by altering the inert component (nitrogen / helium) in a ternary fuel gas mixture. An effective gas transport parameter considering microstructural and geometrical features was derived, enabling a precise quantification of polarization resistances related to gas diffusion and hydrogen electrooxidation. The obtained values were applied to parameterize an existing dc cell model. The model validation in fuel cell and electrolyzer mode showed an excellent agreement between measured and simulated current/voltage characteristics over a wide range of technically meaningful gas compositions and operating temperatures.
\end{abstract}

\section{Introduction}

Nickel / yttria-stabilized zirconia (Ni/YSZ) fuel electrodes represent state of the art electrodes in order to reach out for high performance and durability. Still, the resistance towards Ni coarsening or depletion and redox stability remains expandable (1). This can be achieved by applying a nickel / gadolinium-doped ceria (Ni/CGO) cermet leading to more resilient electrodes towards carbon deposition (2), sulfur poisoning $(3,4)$ and redox stability (5) as well as improved electro-catalytic activity (1). The higher robustness of $\mathrm{Ni} / \mathrm{CGO}$ electrodes is due to the mixed electronic/ionic conductivity of CGO $(6,7)$ at high temperatures and reducing atmosphere (8). In comparison to Ni/YSZ fuel electrodes, the charge transfer reactions are no longer restricted to active three phase boundaries that have to have a direct contact with the nickel-, the electrolyte- and the pore-matrix (8). Nevertheless, there is a demand for nickel as a catalyst (9-11) as a pure CGO-layer results in a drastic increase of the polarization resistance by about two orders of magnitude (12). Furthermore, a multilayer fuel electrode with a CGO layer between the electrode and electrolyte is preferably used in order to increase performance and tolerance against poisoning effects $(12,13)$.

However, in the case of full cells exhibiting a Ni/CGO fuel electrode, an unambiguous process assignment by electrochemical impedance spectroscopy (EIS) measurements and subsequent distribution of relaxation times (DRT) analysis was not achieved up to now, since different processes in fuel and air electrode strongly overlap in the spectrum. In a first step, symmetrical cells can be used in order to separate fuel and air electrode 
processes. Furthermore, the charge transfer and gas diffusion at the Ni/CGO fuel electrode also strongly overlap in the impedance spectra $(3,13-15)$. The latter is caused by the oxygen non-stoichiometry of $\mathrm{CGO}$, which results in a large chemical capacity, shifting the relaxation frequency of the charge transfer process to lower relaxation frequencies $(6,14)$. To overcome this issue and visualize the gas diffusion process, gas mixtures containing different inert gases can be applied as shown for Ni/YSZ (16) and $\mathrm{Ni} / \mathrm{CGO}(15,17,18)$ in previous studies.

Based on the approach by Leonide et al. $(19,20)$ this work strives for the characterization of an electrolyte-supported solid oxide cell (ESC) with Ni/CGO fuel electrode, 3 mol-\% yttria-stabilized zirconia (3YSZ) electrolyte and LSCF air electrode as well as the development of a zero-dimensional cell model for fuel cell and electrolysis mode $(20,21)$. Therefore, a comprehensive understanding and quantification of the individual loss processes occurring in a solid oxide cell is needed, which is also crucial regarding targeted cell development (22). In order to deconvolute the individual loss mechanisms in a solid oxide cell, EIS and the subsequent DRT analysis represent powerful methods. This approach has been successfully demonstrated for electrolytesupported cells (ESC) (16,23), anode-supported cells (ASC) (20) and metal supported cells (MSC) $(24,25)$. Applying this methodology, the physicochemical loss processes occurring in the cells can be identified by their relaxation frequencies and characteristic operating parameter dependencies. The quantification is realized by means of complex non-linear least square (CNLS)-fitting. Based on the obtained results, zero-dimensional dc cell models, which are based on common electrochemical approaches as ButlerVolmer and Fick's laws, can be developed and parameterized.

In this study, we present a method for the deconvolution of gas diffusion and activation polarization within the Ni/CGO fuel electrode of an ESC by EIS measurements. By quantifying the associated electrochemical losses, a zero-dimensional cell model is parameterized, which is capable for predicting the cell performance over a wide technically relevant SOC operating range.

\section{Modeling}

The development of a zero-dimensional dc performance model requires knowledge about the individual loss mechanisms occurring in the cell. Starting from the open circuit voltage $U_{\mathrm{OCV}}$, the cell voltage $U_{\text {cell }}$ is calculated by subtracting ohmic losses $\eta_{\mathrm{ohm}}$, activation losses at the fuel electrode (FE) $\eta_{\text {act,FE }}$ and the air electrode (AE) $\eta_{\text {act,AE }}$ as well as gas diffusion losses at the fuel $\eta_{\text {diff,FE }}$ and air electrode $\eta_{\text {diff,AE }}$ [1]. The equations describing the individual loss mechanisms are given in (20).

$$
U_{\text {cell }}=U_{\mathrm{OCV}}-\eta_{\mathrm{ohm}}-\eta_{\mathrm{act}, \mathrm{FE}}-\eta_{\mathrm{act}, \mathrm{AE}}-\eta_{\mathrm{diff}, \mathrm{FE}}-\eta_{\mathrm{diff}, \mathrm{AE}}
$$

Such OCV minus losses model does not only enable a performance prediction over a wide range of operating parameters but also provides quantitative information about the different voltage losses limiting the cell performance (26). 


\section{Experimental}

In this work planar electrolyte-supported cells with an active cell area of $1 \mathrm{~cm}^{2}$ were investigated. The cells exhibited a Ni/CGO fuel electrode, a 3 mol- $\%$ YSZ (3YSZ) electrolyte substrate and an LSCF air electrode. Additional CGO layers were placed in between electrodes and electrolyte. The layer thicknesses were analyzed by scanning electron microscopy (SEM) yielding in a thickness for the fuel electrode of approx. $24 \mu \mathrm{m}$, for the electrolyte of approx. $85 \mu \mathrm{m}$ and for the air electrode of approx. $30 \mu \mathrm{m}$. In order to study the processes at cathode and anode individually, symmetrical cells with the identical electrodes were applied.

Testing of full and symmetrical cells was performed in a test bench described in (27). The fuel is supplied by a gas mixing unit via mass flow controllers providing gas mixtures of hydrogen $\mathrm{H}_{2}$, oxygen $\mathrm{O}_{2}$ as well as the inert gases nitrogen $\mathrm{N}_{2}$ and helium $\mathrm{He}$, respectively. A total flow rate of $250 \mathrm{sccm}$ is set at each electrode side. Steam is produced in an upstream combustion chamber by mixing oxygen to the fuel. This enables a stable fuel humidification of up to $100 \% \mathrm{H}_{2} \mathrm{O}$.

After mounting the cell in the test rig, a predefined startup procedure was performed. In the following testing phase, impedance spectra and CV-characteristics were measured at systematically varied operating conditions. The spectra were acquired by a Solartron 1260 frequency response analyzer using a pseudo-potentiostatic mode (amplitude $\leq$ $12 \mathrm{mV}$ regarding the polarization resistance (27)). The frequency was varied in between $30 \mathrm{mHz}$ and $1 \mathrm{MHz}$ with 12 points per decade. All experiments were conducted under open circuit conditions (OCV), except for the determination of the charge transfer coefficients $\alpha$. In total about 500 impedance spectra were measured in a wide range of gas compositions in a temperature range from $600{ }^{\circ} \mathrm{C}$ to $900{ }^{\circ} \mathrm{C}$.

The validity of the measured spectra was verified by a Kramers Kronig Test (28). Moreover, after each variation a reference measurement was conducted. The deviation between these spectra was less than $2 \%$ proving that ageing effects can be neglected throughout all measurements.

\section{Results and Discussion}

Regarding a first analysis of processes at the cathode and the anode, impedance spectra of a full cell shall be compared with those of the electrodes taken from symmetrical cell measurements (figure 1). Figure 1 (a) shows the spectrum of the full cell, (b) of the LSCF air electrode and (c) of the Ni/CGO fuel electrode. It should be noted that in (b) and (c) the spectrum of a single electrode is displayed, i.e. the measured spectrum of the symmetrical cell divided by two, whereas in the further figures the full spectra and the related DRTs of the symmetrical cells are displayed. The different ohmic resistances can be explained by different electrolyte thicknesses of the cells. The visible deviation between the full cell and the addition of fuel and air electrode impedance taken from symmetrical cell measurements might originate from minor leakages in the full cell measurement that can be excluded in symmetrical cell measurements as well as minor temperature differences. 
(a)

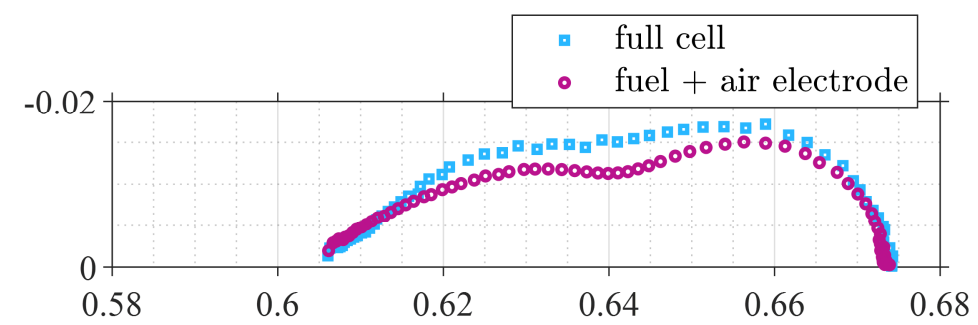

(b)

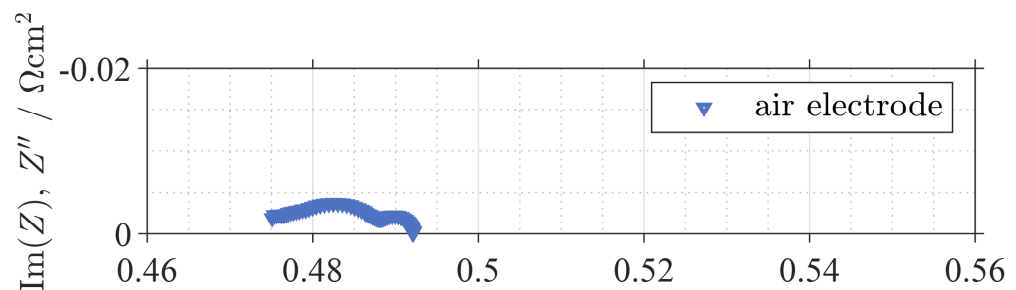

(c)

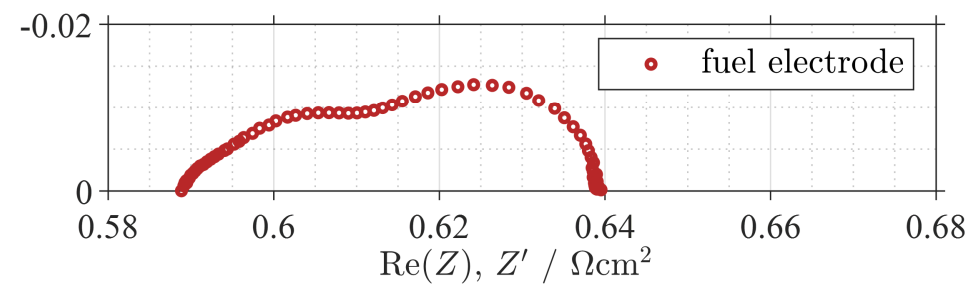

Figure 1. (a) spectra of full cell and sum of fuel and air electrode $\left(T=800{ }^{\circ} \mathrm{C}\right.$, fuel gas mixture of 0.65 atm $\mathrm{H}_{2}$ (balanced with $\mathrm{H}_{2} \mathrm{O}$ ) and synthetic air at the air electrode), (b) the LSCF air electrode $\left(T=800{ }^{\circ} \mathrm{C}\right.$, synthetic air as oxidant) and (c) a Ni/CGO fuel electrode $\left(T=806{ }^{\circ} \mathrm{C}\right.$, fuel gas mixture of 0.65 atm $\mathrm{H}_{2}$ (balanced with $\left.\mathrm{H}_{2} \mathrm{O}\right)$ ).

A more detailed analysis of the LSCF air electrode is not shown in this contribution as similar properties and parameter dependencies as reported in (20) were observed. Recapitulatory, for low oxygen partial pressures a peak at frequencies between $0.3-10 \mathrm{~Hz}$ becomes visible in the DRT. It strongly depends on the oxidant composition but shows approximately no operating temperature dependency, and thus is attributed to the gas diffusion process in the air electrode. It should be noted that the related resistance is negligibly small for technically meaningful operating conditions. In addition, a coupling of the charge transfer with the solid-state diffusion of oxygen ions could be identified in a process around $2-500 \mathrm{~Hz}$, which corresponds to the oxygen reduction in the mixed electronic-ionic conducting LSCF-cathode modelled by a Gerischer element (29).

This paper focuses on results obtained from symmetrical cells with Ni/CGO electrode in order to identify and quantify the processes in the fuel electrode. The challenge to overcome in this contribution shall be illustrated in the DRT of a temperature variation with a fixed gas mixture of $p_{\mathrm{H}_{2}}=0.8$ atm and $p_{\mathrm{H}_{2} \mathrm{O}}=0.2 \mathrm{~atm}$ in figure 2. The temperature covers a range of $600{ }^{\circ} \mathrm{C}$ to $900{ }^{\circ} \mathrm{C}$. According to previous studies, the DRT can be divided into two major peaks in the low frequency $P_{\mathrm{LF}, \mathrm{FE}}$ and middle frequency range $P_{\mathrm{MF}, \mathrm{FE}}(6)$ as indicated in the DRT in figure 2. These contributions include gas diffusion, charge transfer reactions in the electrode and ionic transport in CGO-matrix of the electrode. Obviously, all visible peaks in the DRT are thermally activated. Since a gas 
diffusion process should exhibit a minor and $T^{0.5}$ temperature dependency, the direct correlation of one of those two DRT-peaks to the gas diffusion process is impossible (20). As gas diffusion is an unavoidable process in the fuel electrode, the observed temperature dependency of the DRT-peaks suggest that the gas diffusion process is covered by the thermally activated electrochemical processes $(3,13-15)$. Furthermore, three minor peaks are visible at frequencies above $100 \mathrm{~Hz}$, which are not further analyzed in this study. Suggestions for their origin are given in (6).

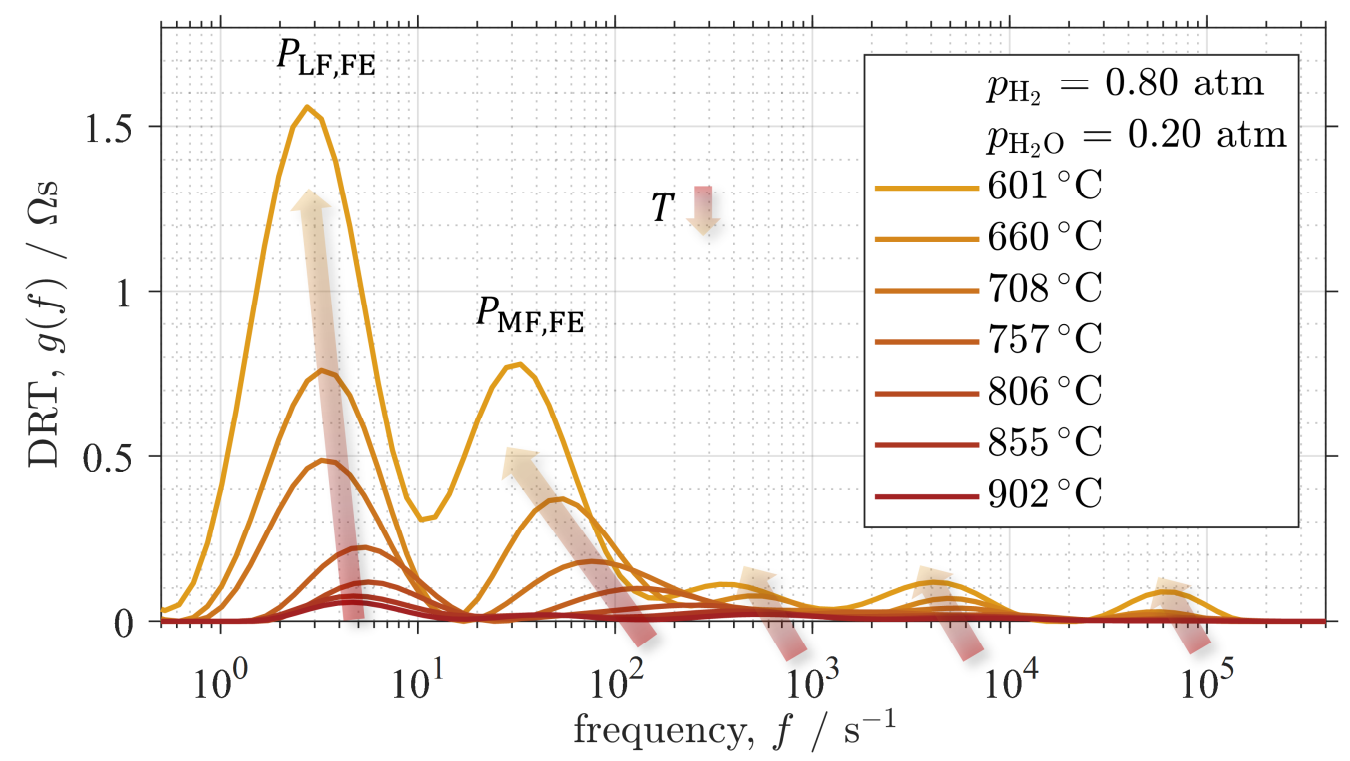

Figure 2. DRTs of spectra measured during a temperature variation between $600{ }^{\circ} \mathrm{C}$ and $900{ }^{\circ} \mathrm{C}$ with a gas mixture of $p_{\mathrm{H}_{2}}=0.8 \mathrm{~atm}$ and $p_{\mathrm{H}_{2} \mathrm{O}}=0.2 \mathrm{~atm}$ of a symmetrical cell with $\mathrm{Ni} / \mathrm{CGO}$ fuel electrodes.

\section{Gas Transport Conditions}

The fuel gas supply of the symmetrical cell is shown in figure 3. Gas transport processes will occur in the gas channels of the flow field (convective and diffusive), the contact mesh (predominantly diffusive) and the porous fuel electrode (diffusive). This complex 3D setup is simplified to a virtual gas diffusion layer with a thickness $L$, whose impact on the gas diffusion resistance is modeled with the approach described in (30). 


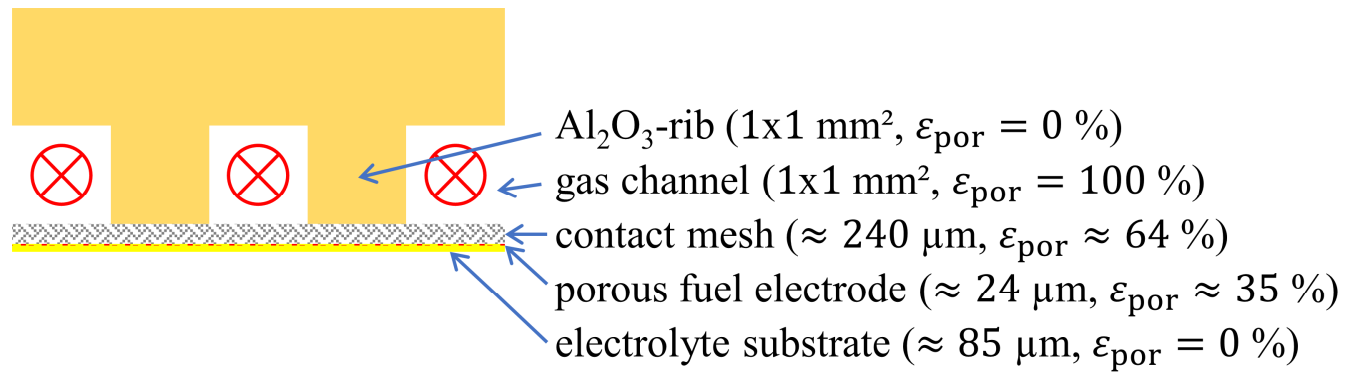

Figure 3. Sketch of the gas transport along the cell's surface in the cell test setup. In the $1 \mathrm{~cm}^{2}$ test benches a stack like gas supply via gas channels is employed. Details can be found in (27).

The dimensions of the gas channel, Ni contact mesh (31) as well as the porous fuel electrode are shown in table I. It becomes obvious that the thickness of the fuel electrode differs by more than one order of magnitude compared to the contact mesh and even more compared to the thickness of the gas channel. Since the gas diffusion resistance as discussed in (30) represents a function of the thickness of the gas diffusion layer $L$, which is dominated by the anode substrate in ASCs (19), the gas diffusion inside the just $24 \mu \mathrm{m}$ thick porous fuel electrode in the investigated ESC presumably can be neglected (6), whereas gas diffusion in the Ni mesh and the gas channels has to be considered. With respect to "pore" diameters $>100 \mu \mathrm{m}$ in gas channel and contact mesh, Knudsen diffusion can be neglected and the gas diffusion coefficients $D_{i}$ are based on molecular gas diffusion solely. The Knudsen number $\mathrm{Kn}$ has been calculated for a temperature of $800{ }^{\circ} \mathrm{C}$ with a gas mixture of $0.5 \mathrm{~atm} \mathrm{H}_{2}$ and $0.5 \mathrm{~atm} \mathrm{H}_{2} \mathrm{O}$ and is shown in table I.

TABLE I. Dimensions and microstructural parameters of gas channel, Ni contact mesh (31) and porous fuel electrode as well as Knudsen criteria Kn. ( ${ }^{(c)} \mathrm{SEM},{ }^{(\mathrm{d})}$ estimated)

\begin{tabular}{|c|c|c|c|c|}
\hline & $\begin{array}{l}\text { thickness } \\
\qquad \mathrm{m} \\
\end{array}$ & $\begin{array}{c}\text { width, } \\
\text { pore diameter } \\
\mu \mathrm{m}\end{array}$ & $\begin{array}{c}\text { porosity } \\
\varepsilon_{\text {por }} \\
- \\
\end{array}$ & Kn \\
\hline gas channel & 1000 & 1000 & 1 & $4.4 \cdot 10^{-4}$ \\
\hline Ni contact mesh $(31)$ & $\approx 240$ & $\approx 250$ & $\approx 0.64$ & $18 \cdot 10^{-4}$ \\
\hline porous fuel electrode & $\approx 24^{(c)}$ & $<0.6^{(d)}$ & $\approx 0.35^{(d)}$ & 0.73 \\
\hline
\end{tabular}

Therefore, the binary gas diffusion coefficients can be calculated by Chapman-Enskog $(32,33)$. Gas diffusion coefficients for components in a gas mixture with more than two components on total are calculated by Wilke (34).

According to Primdahl (30), the gas diffusion resistance $R_{\text {diff,FE }}$ at the fuel electrode can be calculated by equation [2].

$$
R_{\mathrm{diff}, \mathrm{FE}}=\left(\frac{\tilde{R} T}{2 F}\right)^{2} \cdot \frac{L}{\Psi} \cdot\left(\frac{1}{D_{\mathrm{H}_{2}} \cdot p_{\mathrm{H}_{2}}}+\frac{1}{D_{\mathrm{H}_{2} \mathrm{O}} \cdot p_{\mathrm{H}_{2} \mathrm{O}}}\right) \cdot \frac{1}{P_{\mathrm{corr}}}
$$


In this case, $\tilde{R}$ denotes the universal gas constant, $T$ the temperature, $\Psi$ the microstructure parameter within the gas diffusion layer, $L$ the thickness of the gas diffusion layer, $D_{i}$ the molecular gas diffusion coefficient of the component $i, p_{i}$ the partial pressure of the component $i$ and $P_{\text {corr }}$ a conversion factor of $101330 \mathrm{~Pa} \mathrm{~atm}^{-1}$.

In our setup the microstructure parameter $\Psi$ and the thickness $L$ represent unknown parameters, which can be summarized in an effective gas diffusion parameter $G_{\text {eff }}$ accounting for an averaged diffusion length $L$ in a (macroporous) medium with effective gas diffusion properties $\Psi$ described by [3].

$$
G_{\text {eff }}=\frac{\Psi}{L}
$$

This parameter, which is solely depending on geometrical and microstructural features of the test setup and the cell, is not depending on temperature or gas composition and thus can be used to calculate $R_{\text {diff,FE }}$ for arbitrary operating conditions.

\section{Quantification of the Gas Diffusion Process}

In the following a procedure in order to overcome the overlap of activation and gas diffusion polarization in the spectrum with similar time constants is suggested. The subsequent experiment by the application of symmetrical cells with $\mathrm{Ni} / \mathrm{CGO}$ fuel electrodes is designed to enlarge the gas diffusion resistance $R_{\mathrm{diff}, \mathrm{FE}}$ at the fuel electrode (FE) with the help of equation [2] (30).

To analyze the gas diffusion process and quantify $G_{\text {eff }}$, a high accuracy test should be performed at operating conditions enlarging the gas diffusion resistance $R_{\text {diff,FE }}$. As $R_{\text {diff,FE }}$ is proportional to $T^{0.5}$, a high operating temperature of $850{ }^{\circ} \mathrm{C}$ is preferable, which also leads to a decrease of all thermally activated polarization processes. Also, low partial pressures of the reactant $p_{\mathrm{H}_{2}, \mathrm{FE}}=0.1 \mathrm{~atm}$ and the reaction product $p_{\mathrm{H}_{2} \mathrm{O}, \mathrm{FE}}=$ $0.05 \mathrm{~atm}$ with an appropriate balancing by inert gases, nitrogen and helium, are selected. This ensures reducing atmospheres to avoid Ni-oxidation and a sufficient content of steam to keep the charge transfer resistance at a low level. Based on the principles of the kinetic gas theory, we can apply two ternary gas mixtures with different gas diffusion properties as hydrogen and steam diffuse with different velocities in nitrogen or helium respectively. The molecular gas diffusion coefficients at $852{ }^{\circ} \mathrm{C}$ for hydrogen diffusing in the abovementioned steam/nitrogen- and steam/helium-mixture differ by a factor of about 2: $D_{\mathrm{H}_{2},\left(\mathrm{H}_{2} \mathrm{O}, \mathrm{N}_{2}\right)}=0.70 \cdot 10^{-3} \mathrm{~m}^{2} \mathrm{~s}^{-1} / D_{\mathrm{H}_{2},\left(\mathrm{H}_{2} \mathrm{O}, \mathrm{He}\right)}=1.38 \cdot 10^{-3} \mathrm{~m}^{2} \mathrm{~s}^{-1}$.

The measured EIS spectra with corresponding DRT are shown in figure 4 for a symmetrical cell with Ni/CGO fuel electrodes. The application of two different inert gases results in a difference of the polarization resistance of $37 \mathrm{~m} \Omega \mathrm{cm}^{2}$ at a temperature of $852{ }^{\circ} \mathrm{C}$. As the two inert gases are electrochemically inactive, other processes such as charge transfer and ionic charge transport are not affected and the difference in the spectra relies on gas diffusion solely, as shown by Sonn et al. (16) for the Ni/YSZ fuel electrode. This experiment proves the existence of a gas diffusion process, which must be attributed to gas diffusion in the Ni mesh and the flow field. Observing the DRT of the 
symmetrical cell in figure 4 (b), the gas diffusion process becomes visible in a frequency range of $0.4-100 \mathrm{~Hz}$ and thus strongly overlaps with the charge transfer process in the fuel electrode.

(a)
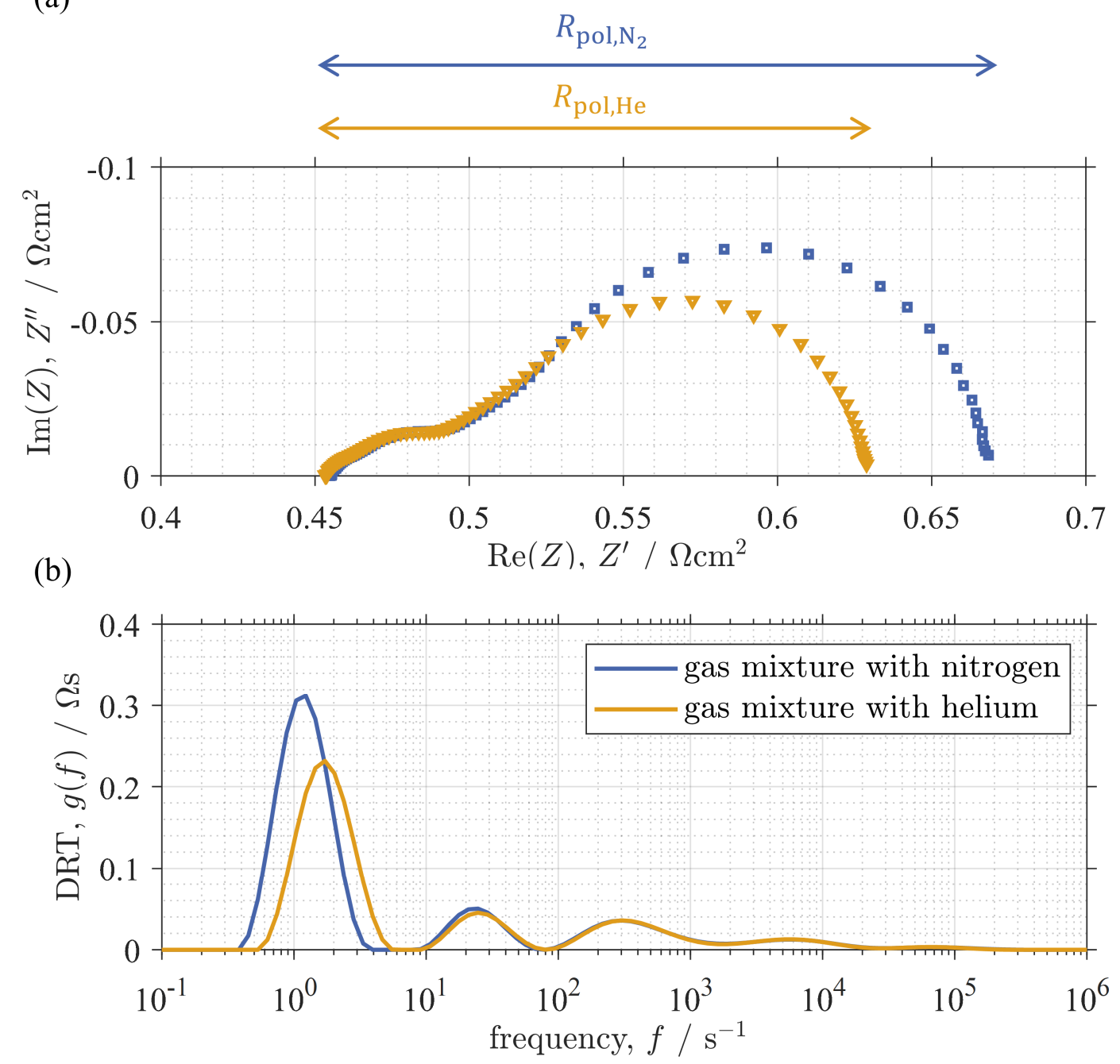

Figure 4. (a) Impedance spectra and (b) DRT of a symmetrical cell with Ni/CGO fuel electrodes with two ternary gas mixtures with the inert gases nitrogen and helium respectively $\left(T=852^{\circ} \mathrm{C}\right.$, gas composition: $0.1 \mathrm{~atm} \mathrm{H}_{2}, 0.05$ atm $\mathrm{H}_{2} \mathrm{O}, 0.85$ atm inert gas).

The effective gas diffusion geometry parameter $G_{\text {eff }}$ shall be obtained from the difference of the polarization resistances indicated in figure 4 (a). Based on the assumptions described above we claim that the difference of the polarization resistance between the gas mixture with nitrogen and helium equals the difference of the gas diffusion resistance in equation [4].

$$
R_{\mathrm{pol}, \mathrm{N}_{2}}-R_{\mathrm{pol}, \mathrm{He}} \equiv R_{{\mathrm{diff}, \mathrm{N}_{2}}}-R_{\mathrm{diff,He}}=\Delta R_{\mathrm{diff}}
$$

We can now determine the unknown geometry parameter $G_{\text {eff }}$ in equation [5]. 


$$
\begin{aligned}
& G_{\mathrm{eff}}=\left(\frac{\tilde{R} T}{2 F}\right)^{2} \cdot \frac{1}{\Delta R_{\mathrm{diff}}} \cdot \frac{1}{P_{\mathrm{corr}}} \cdot \ldots \\
& {\left[\frac{1}{D_{\mathrm{H}_{2},\left(\mathrm{H}_{2} \mathrm{O}, \mathrm{N}_{2}\right)} \cdot p_{\mathrm{H}_{2}, \mathrm{FE}}}+\frac{1}{D_{\mathrm{H}_{2} \mathrm{O},\left(\mathrm{H}_{2}, \mathrm{~N}_{2}\right)} \cdot p_{\mathrm{H}_{2} \mathrm{O}, \mathrm{FE}}}-\frac{1}{D_{\mathrm{H}_{2},\left(\mathrm{H}_{2} \mathrm{O}, \mathrm{He}\right)} \cdot p_{\mathrm{H}_{2}, \mathrm{FE}}}\right.} \\
& \left.-\frac{1}{D_{\mathrm{H}_{2} \mathrm{O},\left(\mathrm{H}_{2}, \mathrm{He}\right)} \cdot p_{\mathrm{H}_{2} \mathrm{O}, \mathrm{FE}}}\right]
\end{aligned}
$$

With the help of the effective geometry parameter $G_{\text {eff }}$ it is now possible to predict the gas diffusion resistance for any set of operating conditions using equation [2].

To evaluate reproducibility appropriate impedance measurements were conducted at different temperatures. The resulting differences in the polarization resistances $\Delta R_{\mathrm{pol}, \mathrm{FE}}$ of the symmetrical cells as well as the subsequent determined geometry parameters are listed in table II. Also, the mean value as well as the standard deviation at each temperature is shown. The calculation of the resulting effective gas diffusion geometry parameter $G_{\text {eff }}$ is conducted with halved resistances to account for one electrode.

TABLE II. Difference of the polarization resistances $\Delta R_{\text {pol,FE }}$ of the symmetrical cells with $\mathrm{Ni} / \mathrm{CGO}$ fuel electrodes for sym-an1 and sym-an2 for a gas mixture of $0.1 \mathrm{~atm} \mathrm{H}_{2}, 0.05 \mathrm{~atm} \mathrm{H}_{2} \mathrm{O}$, balanced with

\begin{tabular}{|c|c|c|c|c|c|c|c|}
\hline \multicolumn{3}{|c|}{ sym-an1 } & \multicolumn{3}{|c|}{ sym-an2 } & \multirow{2}{*}{$\begin{array}{c}\begin{array}{c}\text { mean } \\
\text { value }\end{array} \\
\bar{G}_{\text {eff }} \\
\mathrm{m}^{-1} \\
\end{array}$} & \multirow{2}{*}{$\begin{array}{c}\begin{array}{c}\text { standard } \\
\text { deviation }\end{array} \\
\begin{array}{c}\sigma \\
\mathrm{m}^{-1}\end{array}\end{array}$} \\
\hline $\begin{array}{c}\boldsymbol{T} \\
{ }^{\circ} \mathrm{C}\end{array}$ & $\begin{array}{l}\Delta \boldsymbol{R}_{\text {pol,FE }} \\
\mathrm{m} \Omega \mathrm{cm}^{2}\end{array}$ & $\begin{array}{l}\boldsymbol{G}_{\text {eff }} \\
\mathrm{m}^{-1}\end{array}$ & $\begin{array}{c}\boldsymbol{T} \\
{ }^{\circ} \mathrm{C}\end{array}$ & $\begin{array}{c}\Delta \boldsymbol{R}_{\text {pol,FE }} \\
\mathrm{m} \Omega \mathrm{cm}^{2}\end{array}$ & $\begin{array}{l}\boldsymbol{G}_{\text {eff }} \\
\mathrm{m}^{-1}\end{array}$ & & \\
\hline 753 & 43 & 627.66 & 755 & 42 & 642.93 & 635.30 & 7.63 \\
\hline 803 & 38 & 719.32 & 804 & 41 & 666.85 & 693.09 & 26.24 \\
\hline 852 & 37 & 747.75 & 853 & 40 & 691.84 & 719.80 & 27.96 \\
\hline 902 & 38 & 736.87 & 902 & 38 & 736.87 & 736.87 & 0 \\
\hline
\end{tabular}
$\mathrm{N}_{2}$ and He respectively. The calculation of the resulting effective gas diffusion geometry parameter $G_{\text {eff }}$ is conducted with halved resistances to account for one electrode.

It should be noted that the observed deviations in $G_{\text {eff }}$ are related to rather small variations of the measured polarization resistance $\left(<5 \mathrm{~m} \Omega \mathrm{cm}^{2}\right)$. Furthermore, the resulting $R_{\text {diff,FE }}$ is much smaller than the overall resistance of the cell and will become even smaller for realistic fuel mixtures without $85 \%$ of inert gases. As discussed above, the accuracy in determining $G_{\text {eff }}$ is increasing with increasing operating temperatures. Thus, the values at $902{ }^{\circ} \mathrm{C}$ with $G_{\text {eff }}=736.87 \mathrm{~m}^{-1}$ are more reliable than those at much lower temperatures, where the activation polarization dominates the polarization resistance.

\section{Determination of the Activation Polarization Resistance}

With the objective of establishing a dc cell model, polarization contributions in the impedance spectra of the electrodes can be simplified by RQ-elements (19) and more complex approaches as transmission line models $(22,35)$ can be avoided. To quantify the activation polarization resistance $R_{\mathrm{act}, \mathrm{FE}}$ of the $\mathrm{Ni} / \mathrm{CGO}$ fuel electrode, the low and middle frequency processes including the gas diffusion are summed up to obtain $R_{\text {pol,FE}}$. To account for one electrode the values from the CNLS-fit are divided by 2 . Then the gas 
diffusion resistance $R_{\text {diff,FE }}$ is calculated according to equation [2] and subtracted in equation [6].

$$
R_{\mathrm{act}, \mathrm{FE}}=R_{\mathrm{pol}, \mathrm{FE}}-R_{\mathrm{diff}, \mathrm{FE}}
$$

It is now possible to quantify the activation resistance of the $\mathrm{Ni} / \mathrm{CGO}$ fuel electrode $R_{\text {act,FE }}$, which enables the further parameterization in order to develop a zerodimensional cell model $(20,21)$. In comparison to a direct fitting of the spectra this approach provides a higher accuracy as $G_{\text {eff }}$ is previously determined under ideal conditions enabling a precise calculation of $R_{\mathrm{diff}, \mathrm{FE}}$ for technically relevant operating points.

In the following further extensions regarding the parameterization of a $\mathrm{Ni} / \mathrm{CGO}$ fuel electrode in comparison to the existing model with a Ni/YSZ fuel electrode (20) are presented. For all other parameters no further extensions of the model or its parameterization procedure were necessary and therefore the obtained results for the investigated cell are given in table IV.

\section{Exponent $a$}

The determination of the exponent $a$ in order to describe the hydrogen partial pressure dependency of the fuel electrode's exchange current density follows the approach by Leonide et al. (20). Thus, the exponent $a$ is extracted by a variation of the hydrogen partial pressure with a fixed amount of steam by adding nitrogen as an inert component to the fuel gas mixture. Therefore, a variation of the hydrogen partial pressure $p_{\mathrm{H}_{2}}$ at $0.8 \mathrm{~atm}$, $0.4 \mathrm{~atm}, 0.2 \mathrm{~atm}, 0.1 \mathrm{~atm}$ with a constant steam partial pressure of $0.2 \mathrm{~atm}$ and balanced with $\mathrm{N}_{2}$, at $T=754{ }^{\circ} \mathrm{C}$ is shown in figure 5 (a) for a symmetrical cell. After determining the activation resistance $R_{\mathrm{act}, \mathrm{FE}}$ by subtracting the calculated gas diffusion resistance from the overlapping resistance it can now be plotted as a function of the hydrogen partial pressure in a double logarithmic scale in figure 5 (b). According to Leonide et al. (20), the exponent $a$ can now be identified by the negative value of the slope in figure 5 (b) where $a=0.051$ results from the linear approximation. 
(a)

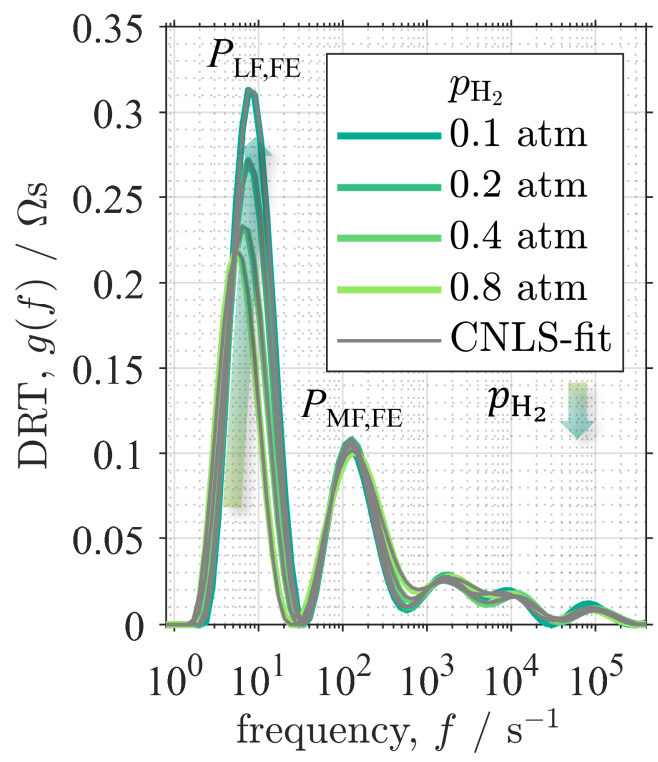

(b)

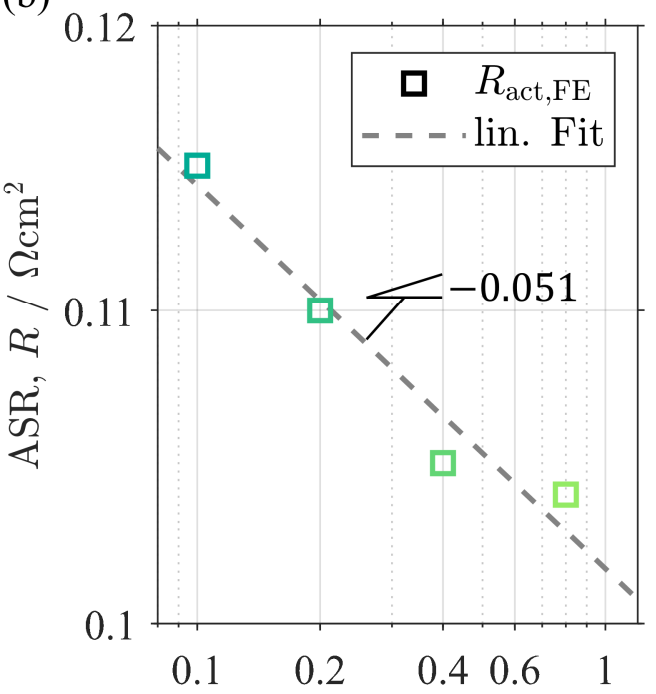

hydrogen partial pressure, $p_{\mathrm{H}_{2}} /$ atm

Figure 5. (a) DRTs of a symmetrical cell with $\mathrm{Ni} / \mathrm{CGO}$ fuel electrodes for a variation of the hydrogen partial pressure $p_{\mathrm{H}_{2}}$ at $0.8 \mathrm{~atm}, 0.4 \mathrm{~atm}, 0.2 \mathrm{~atm}, 0.1 \mathrm{~atm}$ with a constant steam partial pressure $p_{\mathrm{H}_{2} \mathrm{O}}$ of 0.2 atm and balanced with $\mathrm{N}_{2}$, at $T=754{ }^{\circ} \mathrm{C}$. (b) Determination of the exponent $a$, using the ASR-values of a single electrode.

This experiment has been conducted at $598{ }^{\circ} \mathrm{C}, 658{ }^{\circ} \mathrm{C}, 754{ }^{\circ} \mathrm{C}, 804{ }^{\circ} \mathrm{C}, 853{ }^{\circ} \mathrm{C}$, and $902{ }^{\circ} \mathrm{C}$ with the same variation of the gas mixture at each temperature. The results are presented in figure 6 . Whereas in case of the $\mathrm{Ni} / \mathrm{YSZ}$ fuel electrode the exponent $a$ was not depending on temperature. In case of the $\mathrm{Ni} / \mathrm{CGO}$ fuel electrode a significant temperature dependency of the exponent $a$ is observed.

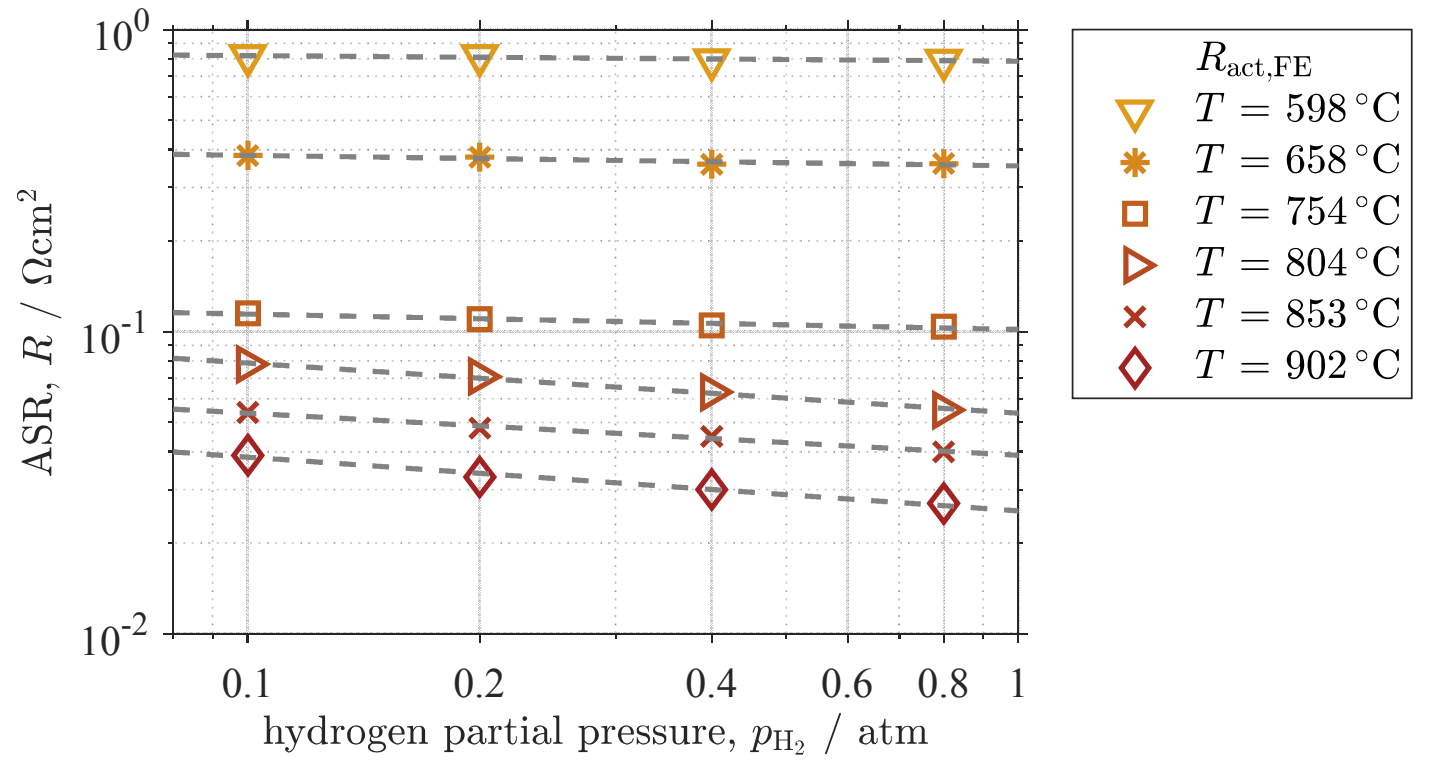

Figure 6. Determination of the exponent $a$ at $598{ }^{\circ} \mathrm{C}, 658{ }^{\circ} \mathrm{C}, 754{ }^{\circ} \mathrm{C}, 804{ }^{\circ} \mathrm{C}, 853{ }^{\circ} \mathrm{C}$ as well as $902{ }^{\circ} \mathrm{C}$. 
The resulting exponents are listed in table III. The differences are ranging over an order of magnitude with the accentuation of two temperature dependent plateaus ranging from approx. $600{ }^{\circ} \mathrm{C}$ to $750{ }^{\circ} \mathrm{C}$ and from $800{ }^{\circ} \mathrm{C}$ to $900{ }^{\circ} \mathrm{C}$ respectively.

TABLE III. Temperature dependency of the exponent $a$ between $600^{\circ} \mathrm{C}$ and $900^{\circ} \mathrm{C}$.

\begin{tabular}{cc}
\hline $\begin{array}{c}\text { temperature } \\
{ }^{\circ} \mathrm{C}\end{array}$ & $a$ \\
\hline 598 & 0.019 \\
658 & 0.035 \\
754 & 0.051 \\
804 & 0.166 \\
853 & 0.139 \\
902 & 0.178 \\
\hline
\end{tabular}

Regarding low temperatures a mean value of $a\left(T=600-750{ }^{\circ} \mathrm{C}\right)=0.035$ with a standard deviation of 0.013 and for higher temperatures a mean value of $a(T=800-$ $\left.900{ }^{\circ} \mathrm{C}\right)=0.161$ with a standard deviation of 0.016 is found. This phenomenon can be explained by the assumptions related to the application of a generalized Butler-Volmer (BV) approach in (20). The coupling of charge transfer and ionic transport in the active electrode volume is described by the overall activation resistance $R_{\mathrm{act}, \mathrm{FE}}$, which is subsequently used to calculate the parameters of the BV-equation. This approach was suitable for the Ni/YSZ-anode as the electrochemical reaction is limited to the three phase boundaries and the ionic conductivity of the YSZ-matrix is not affected by the oxygen partial pressure. Considering a $\mathrm{Ni} / \mathrm{CGO}$ fuel electrode the situation is different. Ionic and electronic conductivity of CGO are depending on the oxygen partial pressure at the fuel electrode, i.e. the fuel gas composition and furthermore the electrochemical activity of the CGO-surfaces will be affected by gas composition and temperature. These complex interactions presumably result in a temperature dependency of the exponent $a$.

\section{Exponent $b$}

Subsequently, the exponent $b$ in order to describe the steam partial pressure dependency of the fuel electrode's exchange current density is determined by a variation of the steam partial pressure with a fixed amount of hydrogen and balanced with nitrogen (20). In figure 7 (a) DRTs of the symmetrical cell are shown for a variation of the steam partial pressure $p_{\mathrm{H}_{2} \mathrm{O}}$ at $0.3 \mathrm{~atm}, 0.2 \mathrm{~atm}, 0.12 \mathrm{~atm}, 0.08 \mathrm{~atm}$ and $0.04 \mathrm{~atm}$ with a constant $p_{\mathrm{H}_{2}}$ of $0.6 \mathrm{~atm}$ and balanced with $\mathrm{N}_{2}$ at $T=755^{\circ} \mathrm{C}$. The activation resistance $R_{\mathrm{act}, \mathrm{FE}}$ is determined by equation [6]. Based on the linear fit of $R_{\mathrm{act}, \mathrm{FE}}$ in figure 7 (b) an exponent for $b=0.2$ can be extracted from the negative value of the slope. 
(a)

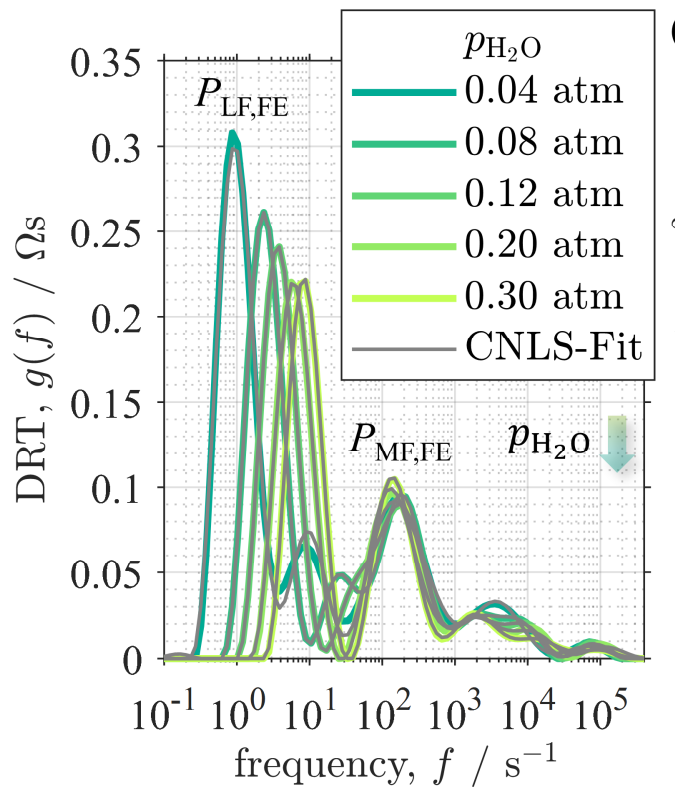

(b)

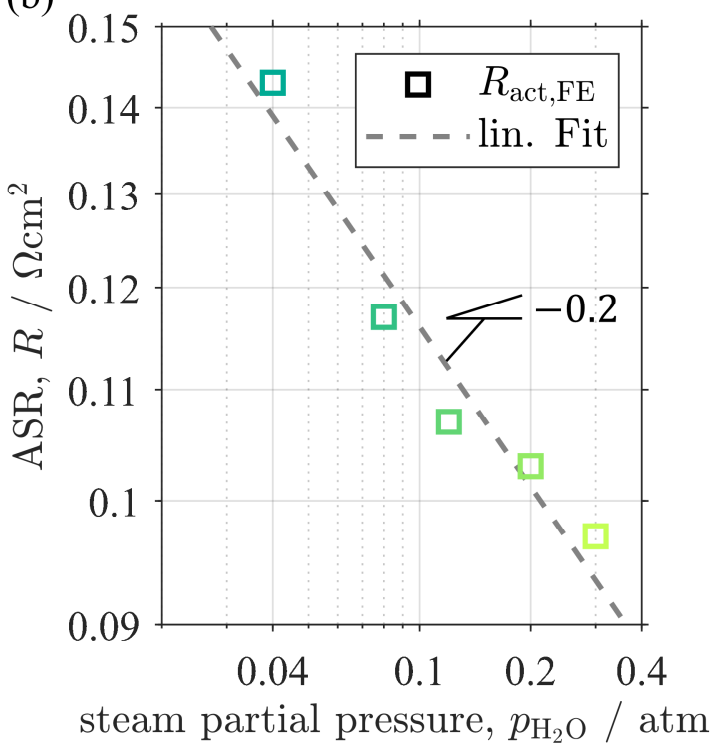

Figure 7. (a) DRTs of a symmetrical cell with $\mathrm{Ni} / \mathrm{CGO}$ fuel electrodes with a variation of the steam partial pressure $p_{\mathrm{H}_{2} \mathrm{O}}$ at $0.3 \mathrm{~atm}, 0.2 \mathrm{~atm}, 0.12 \mathrm{~atm}, 0.08 \mathrm{~atm}$ and $0.04 \mathrm{~atm}$ with a constant $p_{\mathrm{H}_{2}}$ of $0.6 \mathrm{~atm}$ and balanced with $\mathrm{N}_{2}$, at $T=755^{\circ} \mathrm{C}$. (b) Determination of the exponent $b$, using the ASR-values of a single electrode.

Similarly, impedance measurements under these conditions have been performed at $598{ }^{\circ} \mathrm{C}, 658{ }^{\circ} \mathrm{C}, 706{ }^{\circ} \mathrm{C}, 755{ }^{\circ} \mathrm{C}, 804{ }^{\circ} \mathrm{C}, 853{ }^{\circ} \mathrm{C}$ and $902{ }^{\circ} \mathrm{C}$. The results are plotted in figure 8 and reveal a temperature dependency of the exponent $b$ as well.

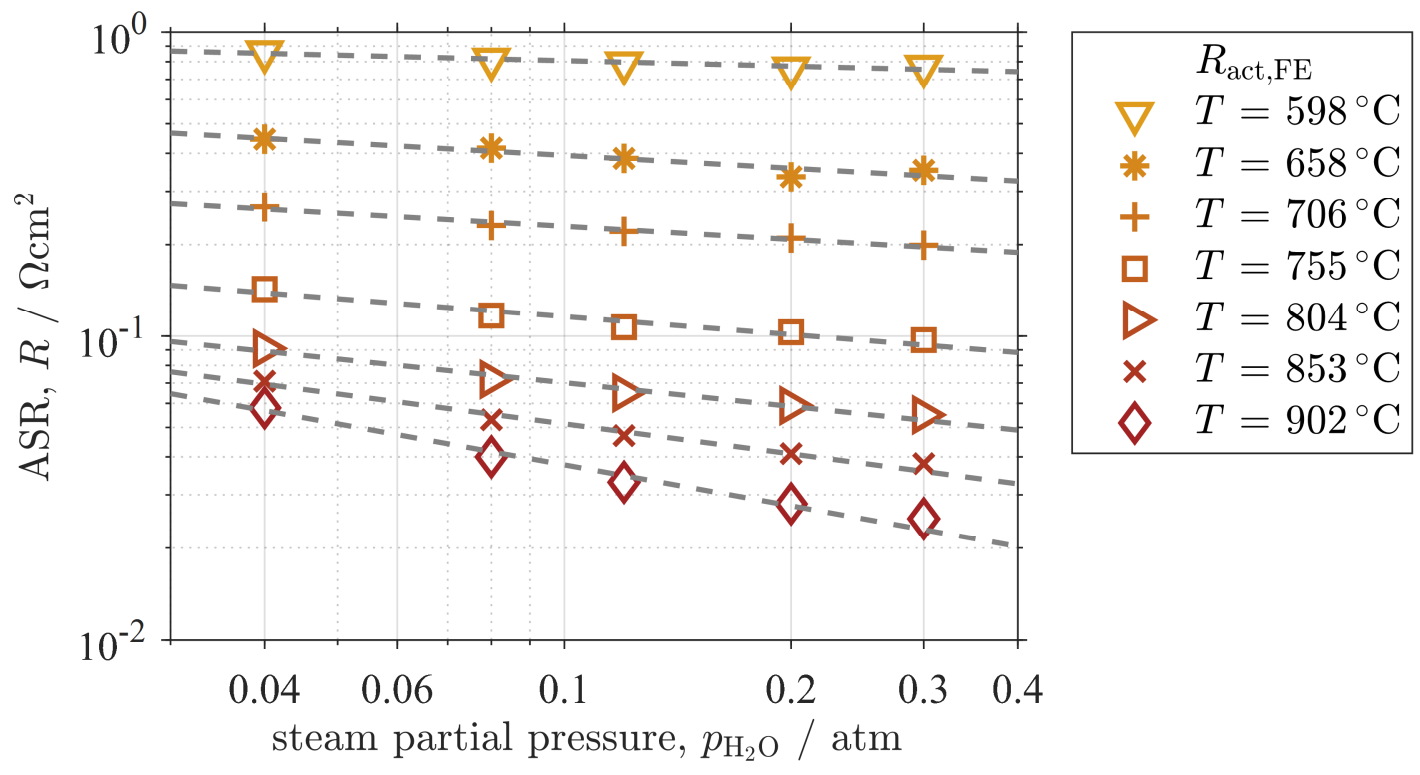

Figure 8. Determination of the exponents $b$ at $598{ }^{\circ} \mathrm{C}, 658{ }^{\circ} \mathrm{C}, 706{ }^{\circ} \mathrm{C}, 755^{\circ} \mathrm{C}, 804{ }^{\circ} \mathrm{C}$, $853{ }^{\circ} \mathrm{C}$ as well as $902{ }^{\circ} \mathrm{C}$.

In addition, the resulting exponents are shown in figure 9 as a function of temperature and reveal a linear character. 


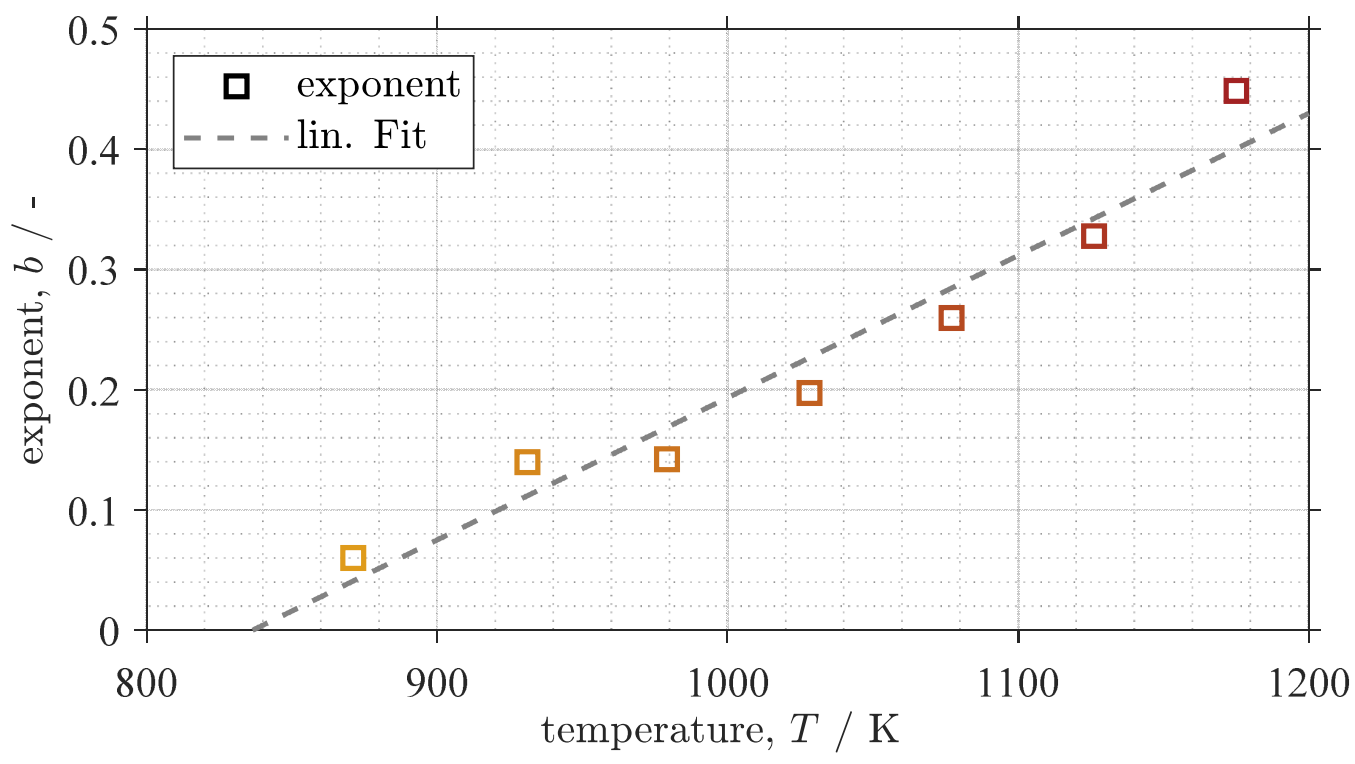

Figure 9. Temperature dependency of the exponent $b$ with a linear fit $\left(R^{2}=0.9435\right)$.

This can be linearly fitted and described by equation [7].

$$
b=\frac{0.0012}{\mathrm{~K}} \cdot T-0.9892
$$

\section{$\underline{\text { Ohmic Losses }}$}

In order to quantify the ohmic losses the thermal behavior of the area specific ohmic resistance $R_{\mathrm{ohm}}(T)$ is investigated for a full cell. Considering that the ohmic losses are generally dominating the overall losses in an ESC, which is even enhanced by the $3 \mathrm{YSZ}$ electrolyte material, the temperature dependency of the activation energy cannot be neglected. To account for this, the ohmic resistance is fitted by a second-degree polynomial instead of a linear line in the Arrhenius plot. Its derivation (slope) gives the temperature dependent activation energy shown in table IV. 


\section{$\underline{\text { Model Parameters }}$}

The relevant parameters in order to model the current-voltage behavior in a zerodimensional approach are listed in table IV. Apart from the adaptions described above, no further changes in the model and its parameterization (20) were necessary.

TABLE IV. Model parameters of the zero-dimensional cell model (20) adapted to a solid oxide cell with Ni/CGO fuel electrode, 3YSZ electrolyte and LSCF air electrode.

\begin{tabular}{lll}
\hline Parameter & Unit & Value \\
\hline$E_{\mathrm{act}, \mathrm{ohm}}$ & $\mathrm{J} \mathrm{mol}^{-1}$ & $1000 \mathrm{~K} \cdot \tilde{R}\left(2 k_{1} x+k_{2}+\frac{1}{x}\right)$ with $x=\frac{1000 \mathrm{~K}}{T}$ \\
& & \\
$B_{\mathrm{ohm}}$ & $\mathrm{K}\left(\Omega \mathrm{m}^{2}\right)^{-1}$ & $\frac{1000 \mathrm{~K}}{x} \frac{10^{4}}{\Omega \mathrm{m}^{2}} \cdot \exp \left(-\left(k_{1} x^{2}+k_{2} x+k_{3}-\frac{E_{\text {act,ohm }}}{1000 \mathrm{~K} \cdot \tilde{R}} \cdot x\right)\right)$ \\
$k_{1}$ & - & 3.8374 \\
$k_{2}$ & - & 1.9162 \\
$k_{3}$ & - & -5.5970 \\
$E_{\mathrm{act}, \mathrm{FE}}$ & $\mathrm{kJ} \mathrm{mol}^{-1}$ & 90.54 \\
$a\left(T=600-750^{\circ} \mathrm{C}\right)$ & - & 0.035 \\
$a\left(T=800-900^{\circ} \mathrm{C}\right)$ & - & 0.161 \\
$b(T)$ & - & 0.0012 \\
$\gamma_{\mathrm{FE}}(T)$ & & $\mathrm{K}$ \\
$\alpha_{\mathrm{FE}, \mathrm{SOEC}}$ & - & $1.46 \cdot 10^{5}\left(\mathrm{~A} \mathrm{~m}^{-2} \mathrm{~K}^{-1}\right) \cdot\left[0.8^{a(T)} \cdot 0.2^{b(T)}\right]^{-1} \cdot T$ \\
$\alpha_{\mathrm{FE}, \mathrm{SOFC}}$ & - & 0.59 \\
$G_{\mathrm{eff}}$ & $\mathrm{m}^{-1}$ & 0.76 \\
$E_{\mathrm{act}, \mathrm{AE}}$ & $\mathrm{kJ} \mathrm{mol}^{-1}$ & 736.87 \\
$m$ & - & 144.54 \\
$\gamma_{\mathrm{AE}}(T)$ & $\mathrm{A} \mathrm{m}^{-2}$ & 0.42 \\
$\alpha_{\mathrm{AE}}$ & - & $5.47 \cdot 10^{9}\left(\mathrm{~A} \mathrm{~m}^{-2} \mathrm{~K}^{-1}\right) \cdot T$ \\
$\Psi_{\mathrm{AE}}$ & - & $0.65(20)$ \\
\hline
\end{tabular}

\section{$\underline{\text { Model Validation }}$}

The cell voltage can now be modeled with equation [1] and further equations given in (20) as all of the unknown parameters are determined. The model covers operating temperatures from $600{ }^{\circ} \mathrm{C}$ to $900{ }^{\circ} \mathrm{C}$ with arbitrary fuel mixtures of hydrogen and steam in a cell voltage range from 600 to $1400 \mathrm{mV}$. To obtain an excellent agreement with measured $\mathrm{CV}$-characteristics the temperature increase due to self-heating of the cell has to be considered in the model. This was realized by using the cell temperature measured by a thermocouple approx. $2 \mathrm{~mm}$ above the cell surface. Furthermore, the measured open circuit voltage is used in order to correct minor leakages below $2 \%$ in the test bench. Exemplary, a validation is shown for a fuel gas mixture of 0.65 atm $\mathrm{H}_{2}$ in figure 10 (a) and 0.35 atm $\mathrm{H}_{2}$ in (b) (balanced with $\mathrm{H}_{2} \mathrm{O}$ ) and synthetic air at the air electrode. 
(a)

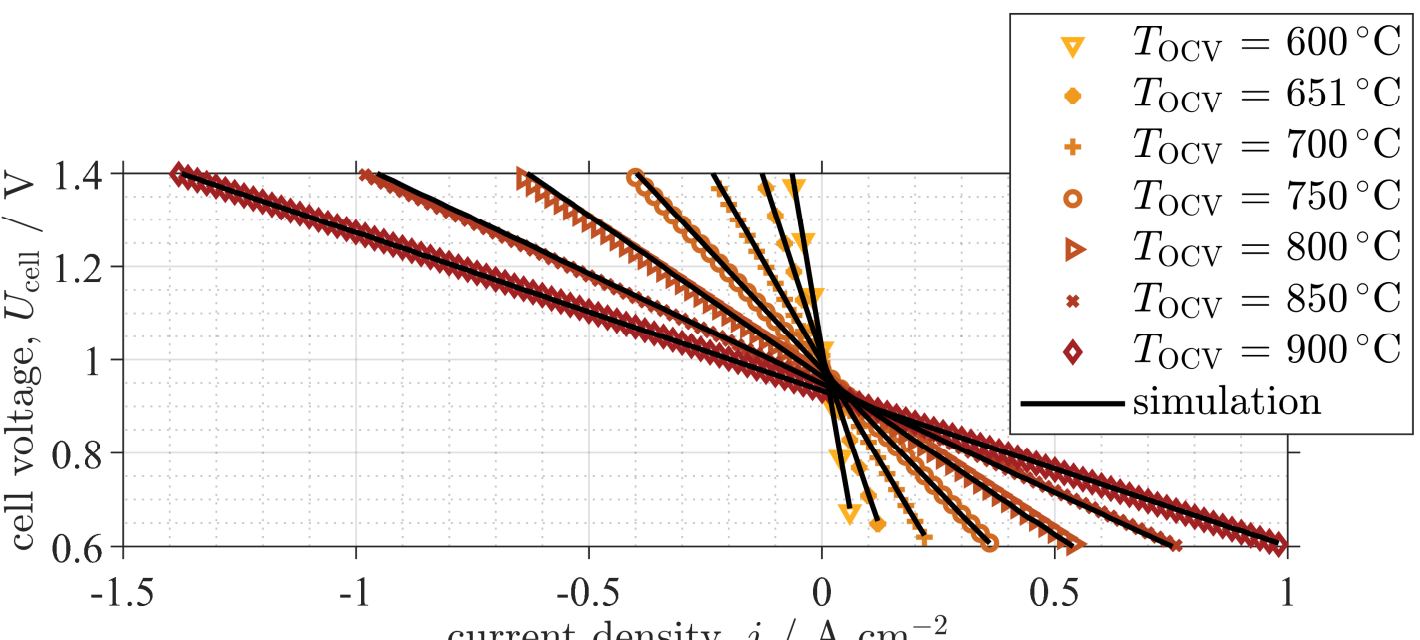

(b)

current density, $j / \mathrm{A} \mathrm{cm}^{-2}$

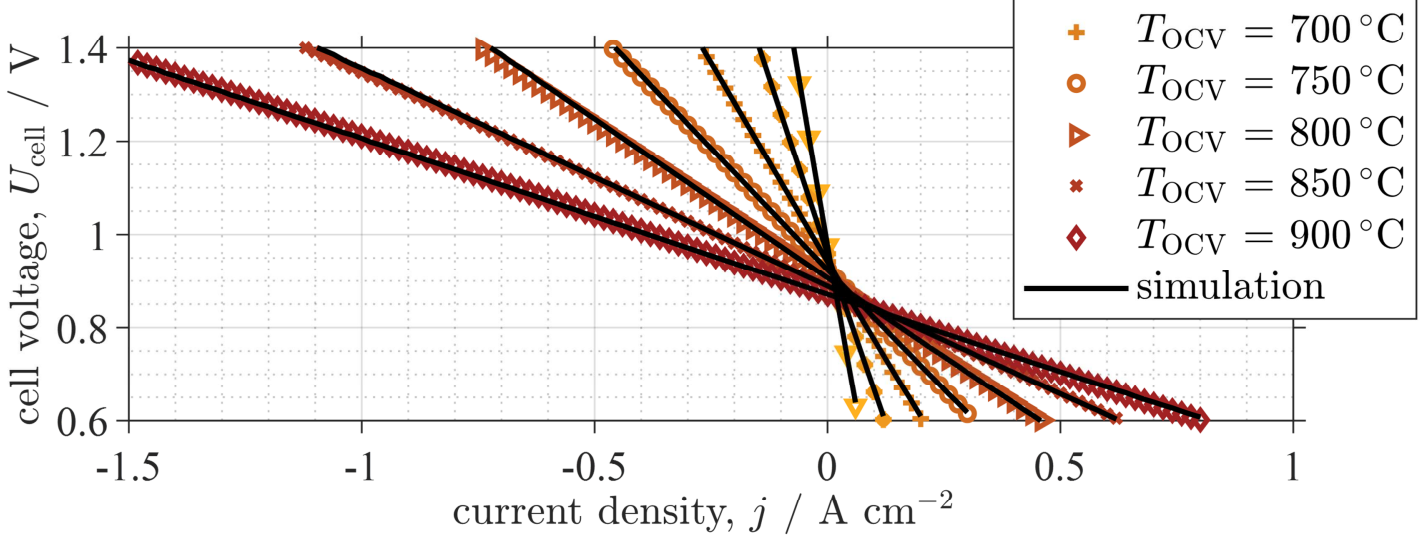

Figure 10. Variation of temperature between $600{ }^{\circ} \mathrm{C}$ and $900{ }^{\circ} \mathrm{C}$ with measured as well as simulated (continuous line) current-voltage characteristics for SOEC and SOFC mode with a fuel gas mixture of 0.65 atm $\mathrm{H}_{2}$ (a) and of 0.35 atm $\mathrm{H}_{2}$ (b) balanced with $\mathrm{H}_{2} \mathrm{O}$ and synthetic air as the oxidant.

The developed zero-dimensional cell model represents the measured current-voltage behavior in excellent agreement with a deviation $\leq 3 \%$ for both SOFC and SOEC mode. The remaining deviation between calculated and measured current-voltage curves is most probably caused by the difference between the internal cell temperature (electrolyte temperature) and the measured temperature (36).

It is now possible to quantify the individual loss contributions (figure 11). Regarding the investigated ESC the ohmic losses are dominating the cell performance as expected. An about one order of magnitude smaller overvoltage has to be attributed to the activation losses at the fuel electrode. The fuel and air electrode gas diffusion losses as well as the air electrode activation losses (testing with synthetic air) are in the range of a few $\mathrm{mV}$ only and thus can almost be neglected. Gas diffusion losses in the cathode can only be analyzed at very low oxygen partial pressures in the applied setup. It should be 
noticed that this can change drastically if the cell is contacted by a thin contact layer in a stack (37).

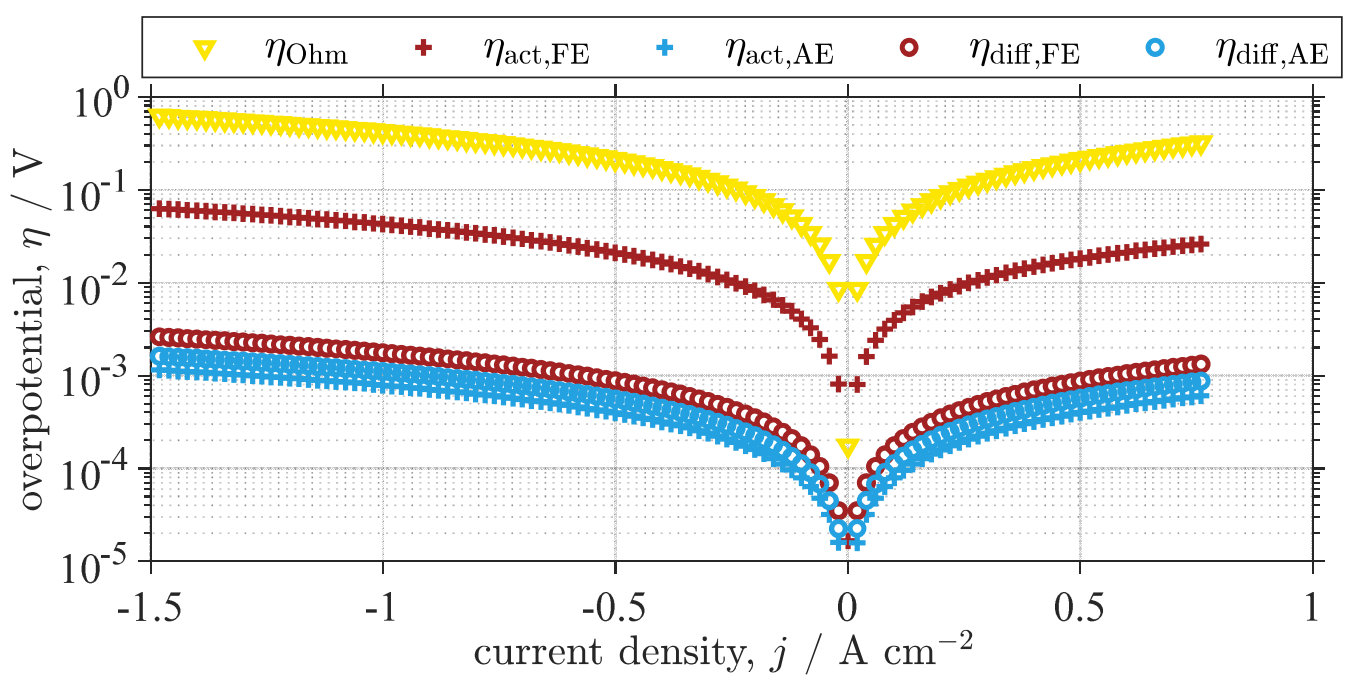

Figure 11. Absolute values of the ohmic $\eta_{\mathrm{ohm}}$, activation $\eta_{\mathrm{act}, \mathrm{FE} / \mathrm{AE}}$ as well as gas diffusion losses $\eta_{\text {diff,FE/AE }}$ as a function of the current density $j$ in SOEC and SOFC mode with a fuel gas mixture of 0.65 atm $\mathrm{H}_{2}$ (balanced with $\mathrm{H}_{2} \mathrm{O}$ ) and synthetic air at the air electrode with $T_{\mathrm{OCV}}=850{ }^{\circ} \mathrm{C}$.

\section{Conclusion}

In this contribution, we presented a zero-dimensional dc model of an electrolytesupported cell with a Ni/CGO fuel electrode. The experimental parameterization via electrochemical impedance spectroscopy enables the model to precisely predict currentvoltage characteristics over wide temperature and gas composition ranges. In order to carry out an unambiguous process identification and subsequent quantification of the loss contributions, the $\mathrm{Ni} / \mathrm{CGO}$ fuel electrode required a methodology for isolating and quantifying the gas diffusion process at the fuel electrode. This was implemented by altering the inert gas component in a ternary fuel gas mixture. The difference in polarization resistances between two different inert gas components, namely nitrogen and helium, can be used to determine an effective gas diffusion geometry parameter, which enables the calculation of the gas diffusion resistance for arbitrary operating conditions. Using this procedure, the loss contributions of gas diffusion and activation within a $\mathrm{Ni} / \mathrm{CGO}$ fuel electrode have been successfully separated and quantified for the first time. The excellent capability of the model for accurate cell performance prediction has been shown by the comparison of measured and calculated CV-curves over a wide range of operating conditions in both SOFC and SOEC mode. 


\section{Acknowledgements}

The authors gratefully acknowledge funding from the Helmholtz project "Solar Hydrogen" and from the Bundesministerium für Wirtschaft und Energie (BMWi 03ETB005E). Sincere thanks are given to Kerafol $\mathrm{GmbH}$ for providing the electrolyte substrates as well as to Sunfire $\mathrm{GmbH}$ for producing the test cells.

\section{References}

1. D. Udomsilp, C. Lenser, O. Guillon, and N. H. Menzler, Energy Technol., 2001062 (2021).

2. J. Mermelstein, M. Millan, and N. Brandon, J. Power Sources, 195 (6), 1657, (2010).

3. V. A. Rojek-Wöckner, A. K. Opitz, M. Brandner, J. Mathé, and M. Bram, J. Power Sources, 328, 65 (2016).

4. M. Riegraf, M. P. Hoerlein, R. Costa, G. Schiller, and K. A. Friedrich, ACS Catal., 7, 7760 (2017).

5. F. Thaler, D. Udomsilp, W. Schafbauer, C. Bischof, Y. Fukuyama, Y. Miura, M. Kawabuchi, S. Taniguchi, S. Takemiya, A. Nenning, A. K. Opitz, J. Power Sources, 434, 226751 (2019).

6. M. Riegraf, R. Costa, G. Schiller, K. A. Friedrich, S. Dierickx, and A. Weber, J. Electrochem. Soc., 166 (13), F865 (2019).

7. T. Nakamura, T. Kobayashi, K. Yashiro, A. Kaimai, T. Otake, K. Sato, J. Mizusaki, and T. Kawada, J. Electrochem. Soc., 155 (6), B563 (2008).

8. K. Eguchi, T. Setoguchi, T. Inoue, and H. Arai, Solid State Ionics, 52, 165172 (1992).

9. J. W. Fergus, Solid State Ionics, 177, 1529-1541 (2006).

10. S. Primdahl and M. Mogensen, Solid State Ionics, 152-153, 597-608 (2002).

11. M. Mogensen, S. Primdahl, M. J. Jørgensen, and C. Bagger, J. Electroceramics, 5, 141-152 (2000).

12. A. Weber, T. Dickel, and E. Ivers-Tiffée, EFCF Proceedings, 48 (2016).

13. A. Weber, S. Dierickx, N. Russner, and E. Ivers-Tiffée, ECS Trans., 77 (10), 141 (2017).

14. M. Riegraf, V. Yurkiv, R. Costa, G. Schiller, and K. A. Friedrich, ChemSusChem, 10 (3), 587 (2017).

15. A. Nenning, C. Bischof, J. Fleig, M. Bram, and A. K. Opitz, Energies, 13 (4), 987 (2020).

16. V. Sonn, A. Leonide, and E. Ivers-Tiffée, J. Electrochem. Soc., 155 (7), B675 (2008).

17. P. V. Aravind, J. P. Ouweltjes, and J. Schoonman, J. Electrochem. Soc., 156 (12), B1417 (2009).

18. A. M. Houssain, J. V.T. Høgh, T. Jacobsen, and N. Bonanos, Int. J. Hydrog. Energy, 37 (5), 4309 (2012).

19. A. Leonide, V. Sonn, A. Weber, and E. Ivers-Tiffée, J. Electrochem. Soc., 155 (1), B36 (2008)

20. A. Leonide, Y. Apel and E. Ivers-Tiffée, ECS Trans., 19 (20), 81-109 (2009). 
21. J.-C. Njodzefon, D. Klotz, A. Kromp, A. Weber, and E. Ivers-Tiffée, J. Electrochem. Soc., 160 (4), F313 (2013).

22. S. Dierickx, T. Mundloch, A. Weber, and E. Ivers-Tiffée, J. Power Sources, 415, 69 (2019).

23. H. Schichlein, A. C. Müller, M. Voigts, A. Krügel, and E. Ivers-Tiffée, J. Appl. Electrochem., 32, 875 (2002).

24. A. Kromp, J. Nielsen, P. Blennow, T. Klemensø, and A. Weber, Fuel Cells, 13 (4), 598-604 (2013).

25. Th. Franco, R. Mücke, A. Weber, M. Haydn, M. Rüttinger, N. H. Menzler, A. Venskutonis, L. S. Sigl and, H.-P. Buchkremer, EFCF Proceedings, A0906 (2012).

26. S. B. Beale, M. Andersson, C. Boigues-Muñoz, H. L. Frandsen, Z. Lin, S. J. McPhail, M. Ni, B. Sundén, A. Weber and, A. Z. Weber, Prog. Energy Combust. Sci., 85, 100902 (2021).

27. D. Klotz, A. Weber, and E. Ivers-Tiffée, Electrochim. Acta, 227, 110-126 (2017).

28. M. Schönleber, D. Klotz and E. Ivers-Tiffée, Electrochim. Acta, 131, 20-27 (2014).

29. C. Endler-Schuck, A. Leonide, A. Weber, S. Uhlenbruck, F. Tietz, and E. IversTiffée, J. Power Sources, 196 (17), 7257 (2011).

30. S. Primdahl and M. Mogensen, J. Electrochem. Soc., 146 (8), F2827 (1999).

31. H. Geisler, Finite Element Method (FEM) Model and Performance Analysis of Solid Oxide Fuel Cells, KIT Scientific Publishing, Karlsruhe (2019).

32. E. L. Cussler, Diffusion: Mass Transfer in Fluid Systems, Cambridge University Press, (1995).

33. B. E. Poling, J. M. Prausnitz, and J. P. O'Connell, The properties of gases and liquids, 5. Ed. McGraw-Hill (2007).

34. D. F. Fairbanks and C. R. Wilke, Ind. Eng. Chem., 42 (3), 471-475, (1950).

35. A. Weber, TM Technisches Messen, 88 (1), 1-16 (2021).

36. D. Klotz, J.-C. Njodzefon, A. Weber, and E. Ivers-Tiffée, ECS Trans., 45 (1), 523-530 (2012).

37. H. Geisler, M. Kornely, A. Weber, and E. Ivers-Tiffée, ECS Trans., 57 (1), 2871 2881 (2013). 